\title{
“EL LIBRO MUDO” Y SU LARGA GESTACIÓN
}

\author{
Juan Guerrero Zamora†*
}

Las actuales condiciones de mi salud, un tanto maltrecha, temo que me impidan expresarme aquí con la brillantez, -en el supuesto de que yo sea brillante- debida a semejante auditorio. Les pido perdón de antemano. También me excuso por lo que pudiera parecer atrevimiento: entrar en el tema de los moriscos en general y en particular granadinos, ante personas, algunas de las presentes, que son en el mismo tanto o más versadas que yo. Me curo en salud de esto último advirtiendo que el tema de esta charla no es específicamente el de los moriscos sino, aunque a ellos se refiera, el proceso de gestación de mi última novela El Libro Mudo, singular p or cuanto, según creo, es la única que hay a abordado o acrisolado en ficción uno de los pasajes más sugestivos e indescifrados de nuestra Historia, el de la solemne impostura que constituyeron los llamados libros plúmbeos del Sacromonte y, como antecedente, los hallazgos de la Torre que aquéllos bautizarían Turpiana y que no era sino el alminar o torre vieja de la mezquita may or de Granada, en trance por entonces, cuando los hallazgos, de ser derribada para cristianarse como catedral de Diego de Siloé.

En 1588, año climatérico según los astrólogos, entre ellos Regio Montano, en el que se verían en los cielos espadas y otros portentos, los surcarían peces recamados de cruces y los adornarían, hasta cinco soles diarios, todo ello por la Pomerania y otros lugares de la pasmada Europa, la después Torre Turpiana, al caer demolida, entregó una arqueta que contenía la mitad de unas supuestas tocas de la Virgen, un hueso del protomártir San Estéba, arenas entre negruzcas y azuladas, una tablilla pintada y un curioso pergamino avalado por el mismísimo San Cecilio, legado por su discípulo Patricio y atribuido a San Juan, que en él componía un nuevo apocalipsis. El hallazgo tuvo gran resonancia -curas milagrosas, asambleas, interés de Felipe II que resultaría uno de los beneficiados pues al tocar una mínima parte de las tocas, que hoy se guarda el El Escorial, sanaría de algún alifafe- pero ni las circunstancias granadinas permitieron que el asunto prosperase pues murió el arzobispo Salvatierra ni estaba el horno nacional, princip almente debido a la empresa de la Armada Invencible, para dichos bollos presuntamente celestiales. De modo que pasaron hasta 7 años antes de que otro descubrimiento,

* Conferencia pronunciada en la Universidad de Alicante, Filologías Integradas, el día 1 de diciembre de 1999 
aún más insistente, rescatara del olvido aquel hallazgo y propusiera con mayor peso específico un común proyecto. Lo que en 1595 se desenterró en Valparaíso, extramuros de Granada, fue una veintena de libros incisos en plomo con textos doctrinales en árabe u otras curiosas lenguas, como la hispano-bética. Cuatro láminas también en plomo los anunciaron así como que sus autores, San Cecilio y San Tesifón entre todo un cenáculo, yacían por aquellas inmediaciones, por lo menos lo que de ellos quedó al ser quemados vivos bajo el pérfido Nerón. Ahora sí, la resonancia fue enorme, y a se irá viendo. Aunque todo era falso, como se probaría.

Esta somera exposición, muy incompleta, sólo intenta suministrar, a los que aquí no hay an oído hablar nunca del suceso, los datos imprescindibles para que puedan entender lo que ha de venir. A éstos prevengo, de paso, que la factura de los libros plúmbeos en nada era semejante a la de un libro en nuestro concep to común. Lo digo porque, al aparecer mi novela, alguien me preguntó cuánto pesaban los plomos del Sacromonte. Estos estaban formados por obleas o, digamos, medallones de plomo muy delgado cuy a fábrica no debió de ser difícil, aunque algo más, eso sí, que la de los huesos calcinados que los acompañaron. Y y a basta con estos prolegómenos.

Si los editores de obras de ficción no huy esen como gato escaldado ante todo lo que suene a erudito, yo habría podido añadir a mi libro el ap éndice bibliográfico que lo verifica en su sustantividad histórica. No haberlo hecho da pie y op ortunidad a este acto de ahora por el que llegarán a conocer cómo pude o supe conjugar lo realmente sucedido con lo imaginado y paralelamente conjeturado para las muchas lagunas que aquello presentaba y presenta.

Dicen que la novela histórica está de moda. No sé si será verdad. Porque lo que observo, salvo honrosa excepción, es una novelística que convierte en pasto de fantasía la historia de manual, ateniéndose a lo repetido sin investigación alguna, simplemente añadiéndole color y, digamos, aventura, sin espíritu crítico de ninguna especie y, a las primeras de cambio, tergiversando por conveniencia o falseando lo histórico. Alejandro Dumas no está tan lejos de nosotros como debiera, por no decir que nos hallamos compadreando con el folletín seudohistórico a lo Sue, Montepin o Ayguals de Izco. Si ése es el fondo, la forma le corresponde y el lenguaje que escoge dicha novelística es en su léxico un puro anacronismo que araña los oídos, por lo menos los míos. No basta un vos en lugar de un usted para reconstruir una ép oca; ni un mero pergamino es característica suficiente -entre otras razones porque el uso del pap el es mucho más antiguo de lo que el tópico supone-, ni con un papiro se reedifica Egipto. Como buenos entendedores, ya ustedes me entienden.

Creo, pues, que mi Libro Mudo, al ap artarse de esa corriente superficial en boga, asume lo que la historia denota, abarca todas sus posibles connotaciones, suple lo desconocido y lo conjetura pero con disciplinada verosimilitud y, con todas las licencias necesarias y complementando su trama con aristas de ficción que son precisamente las que lo definen como 
novela, transcurre diacrónicamente haciéndose camino en el tiempo, porque la historia así se lo impuso, desde fines del siglo XVI y principios del XVII al siglo XVIII y de ellos, ya en libertad del condicionamiento histórico, al nuestro, para p at entizar aquí su vigencia proyectando en nosotros su trascendencia. Es, por ello, sustantiva y rigurosamente histórico; esto, al menos, puedo asegurarlo. Y conviene que lo haga por lo ya dicho y porque los hechos que lo integran permanecen tan ignorados para muchos que, ante su carácter asombroso y casi increíble, podrían atribuirlos a mi imaginación más o menos desbocada.

Cómo desemboqué en estos hechos, por qué los adopté, cómo pude-o quise- acrisolarlos, es lo que voy aquí a poner en orden y concierto aunque tras advertir que su pesca hube de realizarla en río revuelto.

Hace ya muchos años, más de los que desearía contar, un anticuario de Granada, si no recuerdo mal de la Plaza de Bibarrambla, me mostró, entre otros objetos que guardaba en sus vitrinas, un par de obleas de plomo con leyendas incisas en árabe. Satisfizo mi curiosidad ilustrándome con que se trataba de hojas contemporáneas de los famosos libros hallados en el Sacromonte, él dijo la Alcazaba, siglos hacía. Pero como también intentó venderme una gumía en oro y piedras semipreciosas que, a su criterio, provenía de la última dinastía nazarí, poco menos que de Boabdil en persona, y a no tardar descubrí en el Albaicín cómo hábiles orfebres las fabricaban idénticas, supuse que la autenticidad de aquellos no sería may or y di al olvido el asunto sin interesarme siquiera por la fama, desconocida para mí, de aquellos libros de los que me habló.

Pasó bastante tiempo y, hallándome en Lisboa, un librero anticuario de esta ciudad me ofreció un manuscrito castellano en dos infolios que llamó mi atención. No lo adquirí inmediatamente sino, poco después, encargando la gestión de compra y, en caso de concluirse, su posterior restauración a un encuadernador/librero amigo de Madrid. Asíllegó a mi poder, una vez curado de humedades. Era el

\footnotetext{
“Diario del viaje desde Valen cia a Andalucía hecho por D. Francisco Pérez Bayer en este año de 1782. Primera Parte. Contiene su Historia y copias de las inscripciones y monumentos antiguos que ha visto en las ciudades de San Felipe, Gandía, Denia, Alicante, Nueva Tabarca, Cartagena, Lorca, Vera, Almería, Granada, Guadijo, Baeza, Jaén y en las villas de Martos, Porcuna, Montoro, El Carpio y otros lugares de tránsito, con algunas observaciones pertenecientes a la Geografía antigua de España”
}

La segunda parte explícito ya en su título que constituía la continuación del viaje, presentándose 
“Diario del viaje de Andalucía y Portugal hecho por...”

Dispensaré a mis oyentes de la nueva larga lista de lugares visitados en el resto de Andalucía, sitios de Portugal hasta Lisboa y regreso hasta Madrid por Extremadura, y, a cambio, les advertiré sobre lo que también rezaba en el título de la primera parte. Decía:

\footnotetext{
“Lo escribía su autor en los lugares mismos para memoria y su privado uso. Pónense a continuación copias y extractos de varias cartas y documentos pertenecientes a los antiguos hallazgos turpiano e ilipulitano granatenses, recogidos por el autor en el mismo viaje, y sacados de los originales del Sacro Monte de Granada, los quales están hoy depositados en la Real Chancillería de aquella ciudad, y por ellos se confirma y convence haber sido dichos hallazgos fingidos y supuestos”
}

Qué hallazgos turpiano e ilipulitano sería aquéllos, andaba yo preguntándome desde mi absoluta ignorancia en el asunto. La intriga me atraía, pero he de confesar que mayormente me tentaba la obra en su integridad pues, ratón de biblioteca y tesonero bibliófilo, siempre me han atraído los libros de viajes por España, entre los que abundan los ingleses y franceses y escasean los de autores españoles.

Daba por supuesto, a juzgar por la abundancia epigráfica latina inserta en el manuscrito, que su autor no era un cualquiera, pero, a fin de evaluar su obra en el precio justo, procuré identificarlo y si el códice se hallaba o no inédito. Aqué1 resultó ser -y discúlpenme si ya lo saben- persona de gran erudición cuya vida transcurrió entre 1711 y 1794 distinguiéndose como arcediano de la catedral de Valencia, bibliotecario de El Escorial y de Su Majestad, director de la Real Biblioteca de Madrid, primer institutor de los hijos de Carlos III, fundador de la villa de Benicásin, catedrático de hebreo en Salamanca y autor, entre otros escritos, de una apreciada obra de numismática hebreo-samaritana. Figura, además, en el catálogo de autoridades de la lengua. En cuanto al manuscrito del que hablo, no constaba en las bibliografías pero averigüé que existía otra copia del mismo en la Biblioteca Nacional y que permanecía inédito. Aún hoy lo está y la copia de marras, que adquirí, en mi poder. El viaje de Bay er tuvo lugar a sólo un año de que se juzgara y sentenciara a otros falsificadores epígonos de aquellos del siglo XVI. Instado por la aparición de éstos, su curiosidad le llevó a los antiguos y su paciencia le permitió copiar innumerables cartas, documentos, apuntes e informes del famoso bibliógrafo Nicolás Antonio, el filósofo Francisco Suárez, el gran Arias Montano, Bernardo de Aldrete, Román de la Higuera y otros muchos, cada cual dando al arzobispo Pedro de Castro -como luego se verá firmísimo defensor de la autenticidad de las reliquias y libros- su parecer pocas veces negativo. Asimismo, el filólogo valenciano visitó los lugares donde un tal Juan de Flores había hecho aparecer los vestigios amañados y recientemente sometidos a juicio, y daba en su obra cabal 
cuenta de todo. Pero como no rep roducía el texto de los libros plúmbeos, y o seguí sin disp oner del fundamento indispensable -dicho texto no fue publicado hasta 1980, año en que lo hizo Miguel José Hagerty - para aventurarme en una indagación que, de momento, ni siquiera me planteaba.

El hecho de haber sido -una de mis ocupaciones subsidiarias- asesor bibliográfico de una sala de subastas madrileña durante muchos años, me ha dado ocasión de estudiar o por lo menos embelesarme con muchas joy as impresas que difícilmente habría conocido de otro modo. Viene a cuento porque así, si no recuerdo mal, los ochenta grabados de Hey lan sobre el Sacromonte vinieron a mis manos; me hice con la “Historia de los falsos cronicones”, de 1868, donde José Godoy Alcántara rescató el asunto, para denostarlo, del largo olvido en que se hallaba; el "Discurso de la certidumbre de las reliquias descubiertas en Granada desde el año de 1588 hasta el de 1598”, que Gregorio Lóp ez Madera publicó en 1601, o sea al borde de los hechos; la "Razón del juicio seguido en la ciudad de Granada ante los Ilmos. Srs. D. Manuel Doz, presidente de la R. Chancilleria, D. Pedro Antonio Barroeta y Angel, arzobispo que fue de esta diócesis, y D. Antonio Jorge Galbán, actual sucesor de la mitra, todos del Consejo de S. M., contra varios falsificadores de escrituras públicas, monumentos sagrados y profanos, caracteres, tradiciones, reliquias y libros de supuesta antigüedad”, que editó el famoso Ibarra en 1781; y, entre otros libros, la biografía de curioso título "Mystico ramillete, histórico, chronológico, panegyrico, texido de las tres flagrantes flores del nobilísimo antiguo origen, exemplarísima vida y meritissima fama posthuma del Ambrosio de Granada, Espejo de los Jueces seculares y exemplar de eclesiásticos pastores, el Illmo. y V. Sr. Don Pedro de Castro Vaca y Quiñones”, compuesta por Nicolás de Heredia Barnuevo y que, publicada en 1741, denotaba cómo la convicción de que las reliquias y libros plúmbeos eran auténticos seguía en pie, aun después de siglo y medio, y pese a la condena que, sobre los libros y no sobre las reliquias, había proferido el papa Inocencio XI en 1682.

Estudiando a los cronistas de ép oca -los ya citados y otros que, como cerezas que se enredan entre sí, habían venido a mi alcance-, unánimes en la apología y veneración de los hallazgos, y a cuantos desde Godoy Alcántara, se han pronunciado después de forma incrédula y negativa sobre los mismos - Caro Baroja, Darío Cabanelas, Thomas Kendrick y muy especialmente Ignacio Gómez de Liaño que, en sus Juegos del Sacromonte, ap arecido en 1975, co instruyó al tenor de los plomos poco menos que una cosmogonía de España-, me había impregnado del seductor e intrigante asunto lo suficiente como para que su obsesión no me abandonara. Si la información de la que llegué a disponer era abundante, más copiosas eran las interrogantes que aquéllas dejaban en el aire. Desde que, al socaire vaticano, predominó el criterio de los detractores, se supuso que los libros plúmbeos por los que el Sacromonte, antes Valparaíso, cambió de nombre, no fueron sino una imp ostura. Esta parecía suficientemente 
probada. Pero de sus autores no había certeza, aunque los indicios -desmenuzados sobretodo por Cabanelas- apuntaban a los intérpretes reales Alonso del Castillo y quien pudo ser su yerno, Miguel de Luna, cuyas obras y cartularios -La verdadera historia del Rey Don Rodrigo, 1592, del segundo, y el Sumario e Recopilacion de todo lo romanzado por mi, del primero e inédito hast a 1852- conseguí e indagué. Asimismo, subsistía la incógnita clave: ¿Cómo fue posible tamaña impostura -para la que, generosamente financiados, tuvieron que conjurarse por necesidad intereses tan opuestos como los moriscos y los de sus opresores cristianos viejos- sin que la Inquisición se alertase y, es más, con la entusiasta anuencia, que así aclamó sacrosanto lo sacrílego o al menos apócrifo, de las más doctas y preclaras dignidades del reino, eclesiásticas y seglares, sin excluir al mismísimo Felipe II? Un siglo había pasado ya desde que el fanatismo perp etrara -junto a la razón política- y con el éxodo judío el primero de nuestros virtuales genocidios. E intuía que la impostura del Sacromonte -sólo factible porque supo conciliar objetivos aparentemente inconciliables- no tuvo en su inicio otro fin que el de evitar el segundo genocidio, la expulsión morisca. En reivindicación idéntica a la que años atrás incendiara la rebeldía alpujarreña liderada por Aben Humeya, es decir, y puesto que no es concebible que aquellos pocos airados creyesen que podrían vencer al ejército más poderoso del mundo, la reivindicación del respeto que a todo pueblo se debe. Ahora, igualmente escarnecidos, humillados aún más pertinazmente y bajo la amenaza de un destino sombrío, se alzaron otra vez pero, escaldados por el trágico desenlace que tuvo su ira, con la persuasión como única arma, y optaron por un modo digamos teológico de ejercer sus derechos invocando la convivencia en el plano, para que perdurase, de las ideas y creencias. De forma acaso torpe pero genuina y, desde luego, eficaz hasta más allá de lo previsible, lo que arrostraron no fue sino una temeraria propuesta de sincretismo religioso -al que hoy nos encaminamos todos- que resucitaba el espíritu, o simbiosis, un día reinante en Toledo.

De nada les sirvió, como se sabe, pues fueron cercenados de su patria natural en 1609. Pero que España no advirtiera que, tanto entonces como con el destierro sefardí, amp utaba sendos miembros de su propio cuerpo, y a me parecía razón suficiente como para no compartir la opinión de los muchos que, parándose en el significado peyorativo de impostura, han despachado los plomos con cómodo desdén al cajón de sastre de los falsos cronicones.

Documentándome sobre el contexto, compartí en cambio la perspicacia de los que cifraron en Granada la otra fuerza que coadtuvó en la superchería sin percatarse de que lo era, aquella Granada con hambre de santos, ansiosa por llenar con ellos el vacío cristiano de ocho siglos árabes y poder parangonarse al fin con las Iglesias primadas, aquella Granada a la que, a mayor abundancia, la providencia había enviado a quien se creía elegido por Dios para tan 
martirial designio, el citado arzobispo Pedro de Castro. Cuando al cabo decidí afrontar mi libro mudo, le buscaría las vueltas a éste porque, a no dudar, algún impulso secreto debió mover su desmedido celo en pro de los hallazgos -hasta el punto de que empleó una fortuna en su divulgación, crédito y posterior fama con la construcción de la famosa Abadía-, y creí hallarlo en un trauma filial de adolescente, el que padeciera cuando su padre, Vaca de Castro, pacificador del Perú, hubo de sufrir prisión p or las crueldades y corrup ciones que se le imputaron, de lo cual, aunque fue rehabilitado por el Emperador, padeció la huella hasta su muerte, “quedó llagado hasta la muerte”, como él decía.

De momento, ni siquiera la vigilia de Castro y el fervor granadino me parecían causas suficientes para explicar el éxito del fraude y, buscando, hallé otros dos vectores incidentes.

Reparé en el primero leyendo a Lope de Vega y, en concreto, su Tragedia del Rey Don Sebastián y bautismo del Príncipe de Marruecos, por la cual supe de la existencia del africano Muley Xeque y su tío Abd al-Karim junto a las dos cortes árabes de gente desterrada que el Rey Prudente mantenía en Utrera y Andújar con todos los distintivos y privilegios de su real condición y como advertencia para que el sultán de Marruecos, usurpador del trono que correspondía a Muley Xeque, no se desmandase. Una sesgada afirmación de Jaime Oliver Así en su libro Vida de Don Felipe de África (o sea el nombre cristiano de Muley Xeque), Príncipe de Fez y Marruecos 1566-1621, respecto a la pleitesía que rendían frecuentemente los moriscos al señor marroquí, me condujo a imaginarle, si no a él al menos a su cortesano Abd al-Karim, cómplice de la superchería. El segundo vector me hizo topar con el patrono de todos aquellos mártires de los plomos, es decir Santiago, cuy a tradición compostelana estaba siendo puesta en entredicho por García de Loaisa, aspirante a la mitra de Toledo y, lo que es peor, a instigación de éste, por el cardenal romano Baronio. Si éste llegaba a rechazar la tradición en sus inminentes anales, ¿en qué pararían Clavijo y Las Navas, cuyas batallas el santo peregrino dirigiera? ¿No se zafarían los nobles del voto debido a Santiago desde que lo prometió el rey Ramiro I?, y cuál sería la mengua del cabildo compostelano? A este cabildo de Santiago y a la Orden de su mismo nombre convenía sobremanera que los plomos se acreditasen auténticos y, es más, que aparecieran otros machacando sobre la predicación y sepultura del patrón de las Españas. Otro afluente cómplice para la trama que nos ocupa.

Tantas reflexiones y estudios no sabía si iban a servirme de algo porque historiador no soy sino del teatro y, a mis años, no me atrevería a hurgar en la grande y general Historia, ni siquiera en sus veneros marginales, léase infrahistoria o intrahistoria, como prefieran. Pero mi curiosidad no se extinguía. Reconozcan que no era para menos. El Vaticano, al condenar los plomos, había consagrado las reliquias de los mártires que aquéllos identificaban y de los que la may or parte era desconocida. ¿En nombre de qué coherencia santificaba los huesos quemados 
de gentes de las que no había la menor mención y, en cambio, sepultaba inquisitorialmente sus cédulas de identidad, sin las cuales seguiríamos si saber nada de aquéllos? Era para asombrarse. Castro, en el Concilio calificador de los hallazgos que se celebró en Granada, con gran parafernalia y concurrencia eclesial, en el año de 1600, firme postor de la autenticidad del todo, hubo de atenerse a la bula de Clemente VIII imponiendo el sigilo sobre los libros, pero lo hizo de soslayo, pasando sobre los libros como sobre ascuas y de algún modo abarcándolos en la aprobación unánime -nótese, unánime- de la Junta en favor sólo de las reliquias. Dado el alto número de preclaras y devotas mentes que conformaron dicha Junta, ¿cómo fue posible tanta cautela, tanto sobrentendido? Mi asombro crecía. Para no mencionar otras causas de mi estupefacción, recuérdese que de algún libro plúmbeo intraducible a causa de su ignoto lenguaje, se había dicho, y lo había dicho Bermúdez de Pedraza, docto autor de las Antigüedades de Granada, que estaba escrito en una lengua que, si por entonces no se entendía, sería entendida con el paso de los siglos, o sea en una lengua futura. Convengan conmigo en que, puesta la fe a empecinarse, en este caso superaba con creces a la del carbonero.

A todo esto y aun con disponer de material suficiente, seguía careciendo del núcleo de la cuestión, o sea los textos. Que aparecieron, por fin, en su traducción cast ellana de Adán Centurión, marqués de Estepa, en 1980 gracias al ya citado Hagerty. Simultáneamente, poco importa si algo antes o después, me hice con otra copia de la misma traducción, fidedigna por cuanto, en su primera hoja, advierte con significativa cautela:

\footnotetext{
“Esta es copia de los Libros del Montesanto de Granada. El Doctor Don Gabriel Pasqual y Orbaneja, deán y canónigo de la Santa Iglesia de Almería, calificador del Santo Oficio, electo obispo de Aviano en el Reyno de Nápoles, tiene en su poder esta copia necesitado de ella para distinguir lo verdadero de lo apócrifo. Por estar escribiendo un libro de la vida milagrosa del gran prelado San Indalecio, primero obispo almeriense, un o de los 7 discípulos del Apóstol Santiago que hubo en España, de los quales padecieron martirio en Granada tres, Cecilio, Tesifón e Hiscio. Así lo protesto rindiendo mis dictámenes a la Santa Romana y Católica Iglesia, y así mismo la obediencia al Santo Tribunal de la Inquisición. Assí lo declaro por si por mi muerte se hallare este libro en mi poder”.
}

Esta declaración es de distinta mano a la que escribe el resto del texto; por ello y porque la biografía de San Indalecio, en realidad historia de Almería, anunciada por Pascual y Orbaneja,apareció en 1699, podemos situar la copia que poseo entre dicho año y la fecha en que el de Estepa concluyó, habiendo aprendido antes el árabe para poderlo hacer, su traducción de los plomos, es decir 1632. Por cierto que, al segundo folio de mi copia, figura esta leyenda:

\footnotetext{
“El Prólogo de este libro es del Marqués de Estepa. Porque esta traducción de estos libros está corregida
} 
por él y sus intérpretes y es la más ajustada”

Hagerty se guió por otra, sin duda menos ajustada puesto que se vio obligado a corregirle errores de traducción que en la mía van ya corregidos e incluso, en nota, razonada su exactitud. Se ve que el Marqués de Estepa fue decantando su trabajo con escrupulosidad sólo paralela a su fervor por los plomos.

Los libros plúmbeos, cuy o contenido pude al fin conocer, me parecieron tan fascinantes como la intriga que los envolvía y tanto como los evangelios apócrifos. Ellos, su leyenda, su controversia, eran un puchero demasiado hirviente; dejé que reposara.

Tras los hallazgos, su exaltación y la expulsión morisca, sobrevino un largo silencio -bajo el que, tenaz, discurría la devoción sacramontana-, pero, curiosamente, mediaba el siglo XVIII cuando en el mismo sitio o casi, en la contigua Alcazaba, se produjo otra cosecha de plomos, documentos y lápidas que pronto se revelaron -de los moriscos por entonces no pervivía sino un eco apenas perceptible- urdidos esta vez por gentes eclesiásticas -canónigos patrañeros, prebendados de trepa y curas de diverso pelaje- que, bajo el pretexto de remover la fe por las antiguas reliquias, lo que buscaban era su propio y espúreo provecho. Pese a su condición, no lograron satisfacer sus intereses, que no en balde corría el siglo de las luces y el ilustrado gobierno de Carlos III, y todo acabó, como y a dije, ante los tribunales. Cuando me decidiera a componer mi novela, o lo que fuese, que aún no lo veía claro, con el material de esa segunda impostura del XVIII -trasiego de apellidos y progenies, ardides en latín, sesudas controversias, variopintos sofismas, celosas pesquisiciones y, en fin, todo un patio de Monipodio- podría tejer otro relato tan real como el que correspondiese a la primera superchería, pero y a de entrada lo deseché porque lo que aquí, en el fraude original, veía como historia y trascendencia, allí, en el epígono, se reducía a remedo y se resolvía en folletín. Por eso, de su argumento no me importarían sino algunas pautas y datos; la norma del enredo gótico que los autos del proceso me daban con su tejemaneje de apellidos cambíados, prohijamientos y bastardías en relación a uno de los falsarios; Cristóbal Conde y su mujer María Guerrero; y la persona del más infeliz de todos, Francisco Guerrero, maestro minador que, careciendo de parentesco alguno con aquélla, yo se lo sup ondría, y que, manipulado por el prebendado Juan de Flores para las falsificaciones, acabaría loco por arrepentimiento, no obstante lo cual se le condenaría a la pena más rigurosa de todas las que se infligieron. Es curioso que, tras el minucioso proceso, prevaleciera el corporativismo más flagrante. Al cabo, jueces y reos pertenecían al mismo estamento eclesiástico. Las sentencias contra los culpables fueron tan indulgentes que rayaban en lo simbólico, menos, claro es, las que se dictaron contra los peones seglares y, especialmente, contra aquel infeliz Francisco Guerrero, al que llamaría en mi novela por su nombre real, 
tildándole provisionalmente de loco - hasta que demostrase lo contrario porque de loco le tildaron, y encomendándole relatarse una vida de ficción en la plaza que supuse ser Melilla aunque, en los autos, sólo consta que se le exp atrió a uno de nuestros presidios africanos. Escogería Melilla porque ésta, mi ciudad natal, recién librada del más feroz de sus asedios moros, se hallaba en un consiguiente estado de tensión propicio a la fantasía y me abría un escenario proscrito -aún hoy lo está y de su historia no se diga-idóneo en una novela por la que transitarían predominantemente proscritos -moriscos o agotes, que también los habría, y, sobre todo, errados, es decir pecadores, y en la que tendría buena acogida una población de transterrados de toda laya. En Melilla, para cuya recreación no me hacía falta sino acudir al recuerdo y a la relectura de cuanto tenía acumulado sobre ella, pasaría su vida Francisco Guerrero, en un ambiente jovial, putañero, exótico, fronterizo -que mantendría el hilván entre moros y cristianos recurrente a todo lo largo de la que sería mi obra-, castrense de harapienta marcialidad y épico de andar por casa. Cuando llegara el momento, ese loco penado en Melilla me ayudaría a probar, o a intentarlo, cómo a veces la inocencia -la de los simples de espíritupuede conducir al mismo puerto que la sabiduría pues, como afirmaba el sabio sufista Abenarabí de Murcia, dispares serán las sendas de las caravanas pero al cabo todas incidirán en el único oasis que es Dios.

Y llegó el momento, a principios de los noventa, en que decidí dar una finalidad a todo lo estudiado. En 1994, la colección Adonáis publicó mi poemario Almenara. No tengo que decir cuál era su inspiración porque la declara el título, pero las vivencias o raíces, arábigo-andaluzas, melillenses y tunecinas, de esos poemas me sirvieron de estímulo para configurar en forma novelada todo lo que vengo diciendo y lo que considero su sustrato, el propio hervor de mi sangre, nacida en tierras árabes que fueron el último refugio de los moriscos, como lo fue Túnez, que anualmente visito llevado por un inexplicable impulso.

Durante cinco años hube de sistematizar el berenjenal donde me había metido, conectando materiales y apoy ando documentalmente las varias facetas del contexto, por un lado, del siglo XVI y, por otro, del XVIII. Durante otros dos, compuse tres redacciones de la obra, decantando cada vez más su lenguaje, que me proponía fuera en cada caso distintivo de la época correspondiente -en mi libro, tan escueto en descripciones, el léxico es el paisaje- y procurando que esa utilización de olvidados veneros de la lengua resultara, mediante ciertos ardides aclaratorios, comprensible hoy en día cuando, como afirman las estadísticas, los más entre quienes se expresan en castellano usan de, como mucho, mil quinientos vocablos y, por lo común, sólo quinientos. Uno de los libros de plomo es conocido como El Libro Mudo porque nunca ha sido descifrado. Prohijé su título y concedí voz a su presunto texto con otro imaginado por Miguel de Luna que daría fe de su propia vida y de la falsedad de los hallazgos. Miguel, anonadado por la expulsión que no hubo de sufrir, escondería en Melilla ese libro, ese escarnio 
de la iglesia católica más represora, esa búsqueda de Dios a través de la negación y la mentira. Y mi novela, al modo del género policíaco, se estructuraría al hilo de una pesquisa, al rastreo de un misterioso manuscrito con visos de tesoro. Para mí y algunos otros, la búsqueda de un encubierto manuscrito puede ser tan apasionante como indagar sobre un asesinato y su asesino. Le tocaría al descendiente bastardo de ese Luna, Francisco Guerrero o, de hecho, Pedro de Luna, seguir el rastro mientras a su vez relataba su paso por este mundo, lo que equivale a su paso por la tierra melillense. Y entre la relación doble fraguaría mi novela como un díptico.

Para interrelacionar las dos hojas y hacer exp lícito el nexo profundo de sus significados, ideé un marco que las abarcaría, más exacto sería decir que las abrazaría, confiándolo a otro personaje, actual, con su propio lenguaje a cuestas, y también escindido -como aquellos sus dos ascendientes- entre el doble ramalazo árabe y cristiano de su sangre, demediado por ello, hoy se diría con el corazón partido. Les confieso que en mucho de lo que narra, es transunto de mí mismo y a él, en este mundo nuestro donde la insolidaridad humana acuña nuevos fundamentalismos o integrismos como siempre letales, le encargué asumir el ansia -¿utópica, tal ese centésimo nombre de Dios que nadie logra pronunciar?- de reconciliación que, aunando las hostiles creencias con cuyos dogmas nos aniquilamos, nos lleve a la sola y ecuménica verdad.

Porque esa ansiedad era la mía, ésta es la ventura que mi novela añora. El resto -lo que contiene de rigor histórico incluso en la fabulación de lo que la historia sugiere sin más argumento; lo que conlleva de conjetura fundamentada, propuesta hasta hoy sin formular, conexión nunca trabada de hechos ciertos, despliegue en las connotaciones de la fábula-, ese resto es aventura que se exp lica de por sí, como toda obra literaria, y para la que esta glosa no ha sido más que una invitación, la que dirijo a ustedes.

Y termino. El 7 de febrero del corriente año, D. Antonio Cañizares, arzobispo de Granada, anunció en la Abadía del Sacromonte que el Vaticano ha resuelto devolver los libros plúmbeos junto a los 12 volúmenes que recogen las investigaciones a las que fueron en su época sometidos, entre otros muchos escoliastas, por el eminente padre experto en realidades misteriosas Atanasio Kircher. El interés de esta devolución ¿implica que Granada sigue empecinadamente devota del tesoro martirial y que el actual arzobispo resucita a su antecesor Pedro de Castro?¿O es que el prelado reclama los plomos como lo que son, el último exp onente en Esp aña de la literatura morisca? En cualquier caso, la devolución en sí misma denota por parte de la Santa Sede que ésta rectifica. Si ya ha pedido perdón por sus excesos inquisitoriales, parece pedirlo también p or este ilegítimo secuestro. Pero, en última instancia, ¿no es al pueblo morisco, de cuya ansiedad fueron fruto estos plomos, a quien debería dirigir esa humilde, por fin, demanda de perdón?

El 7 de febrero del corriente año, mientras el arzobispo de Granada anunciaba el regreso 
del tesoro, mi obra El Libro Mudo salía de las prensas, como suele decirse, chorreando tinta. Les doy mi palabra de que carezco de espías tanto en Granada como en el Vaticano. Sólo se trataba de una nueva coincidencia en el juego de espejos que fue y, por lo visto, va a seguir siendo el fascinante tema. 